Article

\title{
Nanoformulation Design Including MamC-Mediated Biomimetic Nanoparticles Allows the Simultaneous Application of Targeted Drug Delivery and Magnetic Hyperthermia
}

\author{
Ylenia Jabalera ${ }^{1,+} \oplus$, Francesca Oltolina ${ }^{1,+}$, Ana Peigneux ${ }^{1}$, Alberto Sola-Leyva ${ }^{2}{ }^{\infty}$, \\ Maria P. Carrasco-Jiménez ${ }^{2}\left(\mathbb{D}\right.$, Maria Prat ${ }^{3,4,5,6,7,8, * \mathbb{D}}$, Concepcion Jimenez-Lopez ${ }^{1, *(D)}$ and \\ Guillermo R. Iglesias ${ }^{9}$ (D) \\ 1 Department of Microbiology, Faculty of Sciences, University of Granada, 18071 Granada, Spain; \\ yjabalera@ugr.es (Y.J.); foltolina@ugr.es (F.O.); apn@ugr.es (A.P.) \\ 2 Department of Biochemistry and Molecular Biology I, University of Granada, 18071 Granada, Spain; \\ albertosola@ugr.es (A.S.-L.); mpazcj@ugr.es (M.P.C.-J.) \\ 3 Dipartimento di Scienze della Salute, Università del Piemonte Orientale “A. Avogadro", Via Solaroli 17, \\ 28100 Novara, Italy \\ 4 Centro di Biotecnologie per la Ricerca Medica Applicata (BRMA), Via Solaroli 17, 28100 Novara, Italy \\ 5 Consorzio Interuniversitario per Biotecnologie (CIB), Località Padriciano 99, 34149 Area di Ricerca, Italy \\ 6 Consorzio Interuniversitario Nazionale per la Scienza e Tecnologia dei Materiali (INSTM), Via G. Giusti 9, \\ 50121 Firenze, Italy \\ 7 Consorzio Interuniversitario di Ricerca in Chimica dei Metalli nei Sistemi Biologici (CIRCMSB), \\ Piazza Umberto I, 1, 70121 Bari, Italy \\ 8 Centro Interdipartimentale di Medicina Rigenerativa (CIMeR), Via Montpellier, 1, 00133 Roma, Italy \\ 9 Department of Applied Physics, Faculty of Sciences, University of Granada, 18071 Granada, Spain; \\ iglesias@ugr.es \\ * Correspondence: maria.prat@med.uniupo.it (M.P.); cjl@ugr.es (C.J.-L.); \\ Tel.: +39-0321-660-662 (M.P.); +34-958-249-833 (C.J.-L.) \\ + These authors contributed equally to this work.
}

Received: 30 July 2020; Accepted: 13 August 2020; Published: 15 August 2020 updates

\begin{abstract}
The design of novel nanomaterials that can be used as multifunctional platforms allowing the combination of therapies is gaining increased interest. Moreover, if this nanomaterial is intended for a targeted drug delivery, the use of several guidance methods to increase guidance efficiency is also crucial. Magnetic nanoparticles (MNPs) allow this combination of therapies and guidance strategies. In fact, MNPs can be used simultaneously as drug nanocarriers and magnetic hyperthermia agents and, moreover, they can be guided toward the target by an external magnetic field and by their functionalization with a specific probe. However, it is difficult to find a system based on MNPs that exhibits optimal conditions as a drug nanocarrier and as a magnetic hyperthermia agent. In this work, a novel nanoformulation is proposed to be used as a multifunctional platform that also allows dual complementary guidance. This nanoformulation is based on mixtures of inorganic magnetic nanoparticles (M) that have been shown to be optimal hyperthermia agents, and biomimetic magnetic nanoparticles (BM), that have been shown to be highly efficient drug nanocarriers. The presence of the magnetosome protein MamC at the surface of BM confers novel surface properties that allow for the efficient and stable functionalization of these nanoparticles without the need of further coating, with the release of the relevant molecule being $\mathrm{pH}$-dependent, improved by magnetic hyperthermia. The BM are functionalized with Doxorubicin (DOXO) as a model drug and with an antibody that allows for dual guidance based on a magnetic field and on an antibody. The present study represents a proof of concept to optimize the nanoformulation composition in order to provide the best performance in terms of the magnetic hyperthermia agent and drug nanocarrier.
\end{abstract}


Keywords: magnetic hyperthermia; magnetic nanoparticles; biomimetic magnetic nanoparticles; MamC; tumor combined dual targeting; doxorubicin

\section{Introduction}

The need to combine therapies to increase efficiency is gaining relevance, especially in the context of cancer [1,2]. Not only is drug combination necessary, but therapy combination too, ideally localized at the target site and possibly by using the same platform for a simultaneous application of several therapies. In the context of cancer, this is especially relevant because all the most consolidated therapies (surgery, radiotherapy, chemotherapy, and photodynamic therapy) are not fully effective, especially chemo- and radiotherapy, which provoke severe side effects due to their lack of specificity [3]. For this reason, alternative strategies are becoming attractive, and among them, magnetic hyperthermia $(\mathrm{MH})$ is one of the most promising [4]. MH is the result of the application of an alternating magnetic field (AMF) to hyperthermia agents (such as iron oxide or gold nanoparticles) that, as a result, generate local heat at the tumor site. Such a local temperature increase induces the apoptosis or necrosis of tumor cells, which are more sensitive than normal healthy cells to the increased temperature of about $43^{\circ} \mathrm{C}[5,6]$. The other advantage of this approach is that $\mathrm{MH}$ can penetrate tissues in depth. Therefore, $\mathrm{MH}$ is a strong candidate to be used along with other more consolidated therapies, such as chemotherapy, to generate a synergy between the two treatments that increases the efficiency of the individual ones.

However, in order to be able to combine both therapies, a magnetic hyperthermia agent must be, at the same time, an efficient drug nanocarrier. To better perform its activity, the nanocarrier/hyperthermia agent should be specifically directed and concentrated at the target site, and this could be reached both by magnetic guidance and by a specific probe recognizing a tumor marker. Magnetic nanoparticles could be a suitable system for this goal. In fact, their magnetic properties and their ability to be functionalized by different molecules, including antibodies or enzymes, make them strong candidates to be used as a multifunctional platform for drug delivery and magnetic hyperthermia [7-9]. Nevertheless, it is difficult to find a magnetic nanoparticle that is efficient for both therapies, in addition to the obvious characteristics of being biocompatible and biodegradable. On one hand, the ideal magnetic nanoparticles should be superparamagnetic, i.e., behave as paramagnetic in the absence of an external magnetic field to avoid aggregation, but displaying a high magnetic susceptibility once an external magnetic field is applied. To increase the efficiency of the magnetic guidance, they should have an optimized magnetic moment per particle. These characteristics would allow the nanoparticle to respond to both a continuous gradient magnetic field used to guide them to the target, and to an alternating magnetic field, used for magnetic hyperthermia. In order to deliver nanoparticles with these characteristics, their composition, size, and shape should be optimized. For instance, magnetite nanoparticles with sizes within the range of 4-27 nm [10-12] and cuboctahedral versus cubic have been demonstrated to show the highest specific absorption rate (SAR) values for magnetic hyperthermia [13]. On the other hand, and to be able to combine magnetic hyperthermia with targeted drug delivery, the magnetic nanoparticles should be easily functionalized with different moieties, e.g., a drug and a probe, and to this goal, they should provide a chemical surface pattern mediating the binding for these molecules.

Inorganic magnetic nanoparticles $(\mathrm{M})$ have proven to be excellent hyperthermia agents because of their small size $(<30 \mathrm{~nm})$, which optimizes their magnetic hyperthermia response by both magnetic Neel and Brownian relaxation, and by hysteresis losses [14,15]. However, this small size also compromises their magnetic moment per particle, and therefore the efficiency of the magnetic guidance [16]. Moreover, these MNPs need the addition of different functional groups to be functionalized with the relevant molecule, a process that shields the already not optimal magnetic moment per particle $[17,18]$. Therefore, inorganic MNPs could be good magnetic hyperthermia agents, but they are not optimal drug nanocarriers. 
On contrary, MamC-mediated biomimetic magnetic nanoparticles (BM), which are synthetized in presence of the MamC magnetosome membrane associated protein from Magnetococcus marinus MC-1, display different properties compared to those of MNPs. This is a consequence of the mediation of the MamC protein in the nucleation and growth of the magnetite crystal, and of its presence of up to $5 \%$ at the surface of the nanocrystal $[19,20]$. Because of the unique template exerted by the protein, the nucleation of the biomimetic magnetic nanoparticles is controlled by MamC, resulting in BM that are larger than most $\mathrm{M}$ (average size of BM in the range 30-40 nm), and display a larger magnetic moment per particle while being superparamagnetic. Another unique feature of these BM is their surface properties. The presence of MamC attached to the surface of the BM provides functional groups to the nanoparticle without the need of additional coating and, also shifts the isoelectric point from $\sim 7$ for $\mathrm{M}$ to 4.4 for the BM [20]. This is crucial in making these BM optimal drug nanocarriers for two reasons: (1) at physiological $\mathrm{pH}$ values, $\mathrm{BM}$ are able to bind positively charged molecules through electrostatic interactions, which are weakened at acidic $\mathrm{pHs}$ (such as those found in tumor microenvironments), allowing the release of the adsorbed molecules [20,21]; (2) thanks to these electrostatic interactions, it is possible to attach to them not only the chemotherapy drug, but also to an active targeting agent, like a monoclonal antibody (mAb), as demonstrated previously by Peigneux et al. [22]. However, although these $\mathrm{BM}$ are optimal drug nanocarriers, they do not display as strong a magnetic hyperthermia response as that exhibited by $\mathrm{M}$ [23].

As a consequence of that, a previous study by Iglesias et al. [23] explored the possibility of mixing $\mathrm{M}$ and $\mathrm{BM}$ in different proportions to come up with a nanoformulation that could be used to simultaneously combine drug delivery and the hyperthermia effect. These authors show how the combination of $75 \% \mathrm{M}$ and $25 \% \mathrm{BM}$ had an optimal response upon the application of an alternating magnetic field and proposed this mix as the optimum nanoformulation for the potential combination of the two therapies. However, in their study, BM were not functionalized, and therefore the potential of this nanoformulation as a drug nanocarrier was anticipated, but not proven. Also, in this case, only magnetic guidance was analyzed.

In the present study, we go further with this previous idea of analyzing mixtures of $\mathrm{M}$ (previously referred as MNP [19]) and BM (previously referred as BMNP [19]) but, in this case, BM are functionalized with the model chemotherapy agent Doxorubicin (DOXO; here referred to as binary BM, i.e., BBM) and a monoclonal antibody (here referred as ternary BM, i.e., TBM). Therefore, the potential use of the multifunctional nanoformulation, which is susceptible of a dual guidance to the target site (mediated by the magnetic field and the monoclonal antibody) and can combine two therapeutic approaches (i.e., drug delivery and hyperthermia) is studied as a proof of concept for future in vivo applications.

\section{Materials and Methods}

\section{1. $M$ and BM Synthesis}

MamC expression and purification were performed as previously described by Valverde-Tercedor et al. [19]. Escherichia coli TOP10 (Life Technologies: Invitrogen, Grand Island, NY, USA) was transformed with the plasmid pTrcHis-TOPO (Life Technologies: Invitrogen) used as a vector of the MamC protein-coding gene (Mmc1_2265) coupled to a hexahistidine tag coding sequence at its $5^{\prime}$ terminus. These cells were grown at $37^{\circ} \mathrm{C}$ and MamC overproduction was induced with isopropyl-1-thio- $\beta$-D-galactopyranoside (IPTG). Once expressed, the purification of the protein was carried out under denaturing conditions by fast protein liquid chromatography (FPLC, GE Healthcare) by using immobilized metal affinity chromatography (IMAC, GE Healthcare, Chicago, IL, USA). Lastly, dialysis was performed for a gradual removal of urea, which allowed MamC to refold progressively, and the purity was evaluated by SDS-PAGE electrophoresis.

The synthesis of pure magnetic nanoparticles (here referred as $\mathrm{M}$ ) was carried out at $25^{\circ} \mathrm{C}$ and $1 \mathrm{~atm}$ total pressure using the following master solution: $\mathrm{Fe}\left(\mathrm{ClO}_{4}\right)_{2}(2.78 \mathrm{mM}), \mathrm{NaHCO}_{3} / \mathrm{Na}_{2} \mathrm{CO}_{3}$ $(3.5 \mathrm{mM} / 3.5 \mathrm{mM}), \mathrm{FeCl}_{3}(5.56 \mathrm{mM})$, and $\mathrm{pH}$ 9, elaborated from oxygen-free stock concentrated solutions 
of the individual compounds (protocol described in $[19,24]$ ). The biomimetic nanoparticles (BM) were obtained by adding the purified MamC protein (at a final concentration of $10 \mu \mathrm{g} / \mathrm{mL}$ ) to the solution used for M. All experiments were done under anaerobic conditions inside an anaerobic Coy chamber ( $96 \% \mathrm{~N}_{2} / 4 \% \mathrm{H}_{2}$, Coy Laboratory Products, Grass Lake, MI, USA). Samples were incubated for 30 days before the solids were magnetically decanted and washed three times with deoxygenated Milli-Q water. The magnetic particles were kept in water inside the Coy chamber until further use.

\subsection{Functionalization of the $B M$}

BM were functionalized with AR-3 mAbs (IgG1), which was raised against the A431 epidermoid carcinoma (ATCC ${ }^{\circledR}$ CRL-1555 ${ }^{\mathrm{TM}}$, Manassas, VA, USA), which was used as immunogen. The mAb was selected for its reactivity against carcinoma cells, including those of the gastro-enteric tract, and indeed it lacks reactivity with normal epithelial cells, as well as with cells of mesenchymal origin, such as fibroblasts, blood cells and sarcomas [25]. The antigen recognized by AR-3 mAb, which because of its specificity for carcinomas was called CAR-3, is a mucin-like molecule of approximately $400 \mathrm{kDa}$ molecular weight and the epitope was found to be of carbohydrate nature, since it is sensitive to the metaperiodate treatment, but not to proteolytic enzymes [26]. BM were functionalized also with the chemotherapeutic agent DOXO (Sigma-Aldrich, Madrid, Spain). In both cases, functionalization was carried out as described by Iafisco et al. [27]. Briefly, $5 \mathrm{mg}$ of BM were mixed with $1 \mathrm{mg} / \mathrm{mL}$ of $\mathrm{mAb}$ or DOXO suspended in HEPES buffer at $\mathrm{pH} 7.4$ for $24 \mathrm{~h}$, inside hermetically closed bottles to avoid magnetite oxidation at $25^{\circ} \mathrm{C}$, in rotation on a wheel. The DOXO-BM complexes were the so-called binary nanoparticles (BBM). Ternary nanoassemblies (mAb-DOXO-BM, here called TBM) were produced with the same protocol in two steps, coupling first the mAb and then DOXO. At the end of each incubation, particles were collected with a magnet and washed three times with HEPES buffer. Supernatants and the washings were mixed and the amounts of $\mathrm{mAb}$ and DOXO measured by UV-Vis spectroscopy ( $\lambda=280$ and $490 \mathrm{~nm}$, respectively) were detracted from the amount initially incubated and similarly measured, to quantify the amounts of bound ligands. Functionalization efficiency was $70 \pm 10 \%$ for DOXO and $40 \pm 10 \%$ for AR-3 mAb corresponding to about $140 \mu \mathrm{g}$ of DOXO and $80 \mu \mathrm{g}$ of $\mathrm{mAb} / \mathrm{mg} \mathrm{BM}$.

\subsection{Nanoparticles Characterization}

The morphology and size of the synthesized nanoparticles were analyzed by transmission electron microscopy (TEM Philips Model CM20, Eindhoven, The Netherlands) equipped with an energy dispersive X-ray spectrometer (EDAX). The size of the particles was analyzed by using Image 1.47 software. The $\zeta$ potential, hydrodynamic radius and hysteresis cycles were measured as already described by García-Rubia et al. [20] using Malvern Zetasizer software (Malvern Instruments, Malvern, Worcestershire, UK) and a superconducting quantum interference device (SQUID) 5 T magnetometer (Quantum Design MPMS XL, San Diego, CA, USA), respectively. Powder X-ray diffraction (XRD) analysis was performed with an Xpert Pro X-ray diffractometer (PANalytical, Almelo, The Netherlands) by using the $\mathrm{Cu} \mathrm{K} \alpha$ radiation, $20^{\circ}-60^{\circ}$ in $2 \theta\left(0.01^{\circ} ; 3 \mathrm{~s}\right)$. Fourier-transform infrared (FT-IR) analysis was carried out using a FTIR spectrometer (model 6600, Jasco, Tokio, Japan) equipped with an attenuated total reflection (ATR) diamond crystal window (ATR ProOne). The surface of the sample was pressed against the ATR window and infrared spectra were acquired. A total of 100 scans were collected in the wavenumber range from 4000 to $400 \mathrm{~cm}^{-1}$, at $2 \mathrm{~cm}^{-1}$ of resolution.

\subsection{Stability Evaluation}

The colloidal stability of the samples was determined optically by means of recording the sedimentation process of the different nanosystems. The time evolution of the phase separation line between the particles and medium of each sample were photographed at certain intervals. Afterwards, the height and volume of each phase were determined through image processing and analyzed. A volume of $0.5 \mathrm{~mL} 30 \mathrm{mg} / \mathrm{mL}$ of these different nanoparticles was shaken in a vortex for $1 \mathrm{~min}$ (time 
zero of the experiment) and allowed to sediment. For each experiment, the end of the sedimentation time was considered when a pellet formed at the bottom of the tube.

\subsection{Hyperthermia Experiments}

A current AC generator was used to perform the hyperthermia experiments. The setup consists of induction heating coils made by 4 turns of water-cooled copper, a power supply, and a chiller to maintain the temperature of the coil. Four frequencies, namely 143, 163, 205, and $273 \mathrm{kHz}$ were selected, with a fixed magnetic field intensity of $12.5 \mathrm{kA} / \mathrm{m}$, measured at the center of the coil, with an AC magnetic probe (NanoScience Laboratories Ltd., Newcastle, UK).

All samples were prepared in plastic 1.5 Eppendorf tubes, with a volume of $0.5 \mathrm{~mL}$ and a concentration of $30 \mathrm{mg} / \mathrm{mL}$. Four types of dispersed systems were evaluated, namely those based on pure magnetic nanoparticles $\mathrm{M}$, pure TBM, and mixtures containing 25\% TBM + 75\% M (25 TBM + $75 \mathrm{M})$ and $60 \% \mathrm{TBM}+40 \% \mathrm{M}(60 \mathrm{TBM}+40 \mathrm{M})$.

For the measurement of hyperthermia, all samples were previously pre-thermized at $37^{\circ} \mathrm{C}$. The temperature increase as a function of time was measured with a fiber optic thermometer (Optocon AG, Dresden, Germany), and the specific absorption rate (SAR) and intrinsic loss power (ILP) of the different systems were calculated [28,29] using Equations (1) and (2):

$$
\begin{gathered}
S A R=\left(\frac{C \cdot V_{s}}{m}\right) \frac{d T}{d t} \\
I L P=\frac{S A R}{f H_{0}^{2}}
\end{gathered}
$$

where $C$ is the volume specific heat capacity of the sample $\left(\mathrm{C}_{\mathrm{H} 2 \mathrm{O}}=4185 \mathrm{~J} / \mathrm{LK}\right)$, vs. is the sample volume $(0.5 \mathrm{~mL}$ in the reported experiments), and $\mathrm{m}$ is the mass of solids in the sample (15 mg).

\subsection{Nanoformulation as Nanocarriers: Effect of Hyperthermia on DOXO Release}

The effect of hyperthermia on the DOXO release from the nanoformulation that yielded better hyperthermia results was evaluated as described by Peigneux et al. [22]. Briefly, an alternating magnetic field (frequency $=130 \mathrm{kHz}, \mathrm{H}=20 \mathrm{kA} / \mathrm{m}$ ) was applied to the suspension of the $25 \mathrm{TBM}+75 \mathrm{M}$ nanoassemblies prepared at $\mathrm{pH} 7.4$ and 5.0, and DOXO release was measured at different time points up to $75 \mathrm{~min}$. At specific intervals, the nanoassemblies were separated from the supernatant using a magnet and the tube was refilled with fresh buffer to continue the following time points. The magnetic field strength was controlled manually to ensure a constant temperature of $43.0 \pm 0.5^{\circ} \mathrm{C}$. Identical samples kept in a thermostatic bath at $43^{\circ} \mathrm{C}$ were used as control. Supernatants were measured 3 times by UV-Vis spectroscopy $(\lambda=490 \mathrm{~nm})$.

\subsection{Cell Cultures}

The HT-29 cell line (ATCC ${ }^{\circledR}$ HTB-38 ${ }^{\mathrm{TM}}$, Manassas, VA, USA), derived from a human colorectal adenocarcinoma, was maintained in Minimum Essential Medium (MEM) supplemented with 10\% heat-inactivated fetal bovine serum (FBS) with $2 \mathrm{mM}$ L-glutamine, $1 \%$ nonessential amino acids, $100 \mathrm{U} / \mathrm{mL}$ penicillin, and $100 \mu \mathrm{g} / \mathrm{mL}$ streptomycin in a humid atmosphere with $5 \% \mathrm{CO}_{2}$ as $37^{\circ} \mathrm{C}$. Cells were splitted when at $80-90 \%$ confluency.

\subsection{Cytocompatibility and Cytotoxicity of the Nanoassemblies}

HT-29 cells were seeded in 96-well plates, incubated for $24 \mathrm{~h}$, and then for $72 \mathrm{~h}$ with 150 or $300 \mu \mathrm{g} / \mathrm{mL}$ of BM, M, TBM, nanoassemblies ( $25 \mathrm{BM}+75 \mathrm{M}$ or $25 \mathrm{TBM}+75 \mathrm{M})$, and equimolar amounts of soluble DOXO coupled to the different nanoassemblies (TBM and $25 \mathrm{TBM}+75 \mathrm{M}$ ). To determine the effect of magnetic hyperthermia on cell viability, in another set of experiments, HT-29 were incubated with the maximum concentration $(300 \mu \mathrm{g} / \mathrm{mL})$ of $\mathrm{M}$, TBM, and the nanoassembly $25 \mathrm{TBM}+75 \mathrm{M}$ 
for $24 \mathrm{~h}$ to allow the internalization of the nanoassemblies. After the incubation time, cells were exposed to AMF for $2 \mathrm{~h}$. Finally, the viability was evaluated by the MTT colorimetric assay, as already described [30]. Briefly, $10 \mu \mathrm{L}$ of the MTT $5 \mathrm{mg} / \mathrm{mL}$ in phosphate buffered saline (PBS) solution was added to the plate, incubated at $37^{\circ} \mathrm{C}$ for $2 \mathrm{~h}$, and supernatants were removed. DMSO was added to dissolve the formazan crystals and the optical density was measured. The value obtained from the analyses of untreated cells run in parallel was taken as $100 \%$ viability and all the other values were normalized to the former. Experiments were performed in triplicates.

\subsection{Statistical Analysis}

Statistical analyses were performed using GraphPad Prism version 8.4.2 for Windows, GraphPad Software (GraphPad Prism, San Diego, CA, USA). For nanoparticles size characterization, size distribution curves and ANOVA statistical analyses were determined from measurements performed on 1000 particles. Averages were considered significantly different if $p<0.05$. For in vitro biological analysis, data represent means \pm SD of three independent experiments performed in triplicate, and statistical analyses were carried on using two-way ANOVA, with a Bonferroni's post-test for grouped analysis. Statistical differences between the treatments were considered significant when $p$ values were $p \leq 0.05\left(^{*}\right), p \leq 0.01\left(^{* *}\right)$, and $\left.p \leq 0.001{ }^{(* *}\right)$.

\section{Results and Discussion}

\subsection{Morphology and Particle Size}

As shown in Figure 1A,B, M display poorly faceted crystals faces, while BM show well defined faces with different morphologies (square, rhombic, or rectangular, among others). The size of $\mathrm{M}$ was up to $30 \mathrm{~nm}$, according to the size distribution histogram obtained from the TEM images measurements (Figure 1C,D), with an average crystal size of $15 \pm 8 \mathrm{~nm}$. On the contrary, BM show a size range from 10 to $60 \mathrm{~nm}$, with an average size of $36 \pm 8 \mathrm{~nm}$. Statistical analysis (ANOVA test) reveals that the size differences between the two types of nanoparticles are statistically significant (at $\alpha<0.05$ ), with a probability of $7.8 \times 10^{-9}$. The XRD patterns of M (Figure $1 \mathrm{G}$ ) and BM (Figure $1 \mathrm{H}$ ) demonstrate the good crystallinity of both types of magnetite nanoparticles, with the diffractions being peaks coincident with those of the reference magnetite. In fact, the diffraction peak with the highest intensity corresponds to the 311 magnetite reflection. The hysteresis loop of $\mathrm{M}$ and BM show the ferromagnetic character of these nanoparticles at $5 \mathrm{~K}$ and with no external field applied, showing remaining coercivity. However, at $300 \mathrm{~K}$, the nanoparticles display zero coercivity in the absence of an external magnetic field, revealing their superparamagnetic behaviour (Figure 1E,F). The magnetization saturation of M and BM at $300 \mathrm{~K}$ is $63 \mathrm{emu} / \mathrm{g}$ and $55 \mathrm{emu} / \mathrm{g}$, respectively, with BM showing less magnetization saturation because of the presence of the $5 \%$ of the MamC in the latter, as previously showed by García-Rubia et al. [20]. 

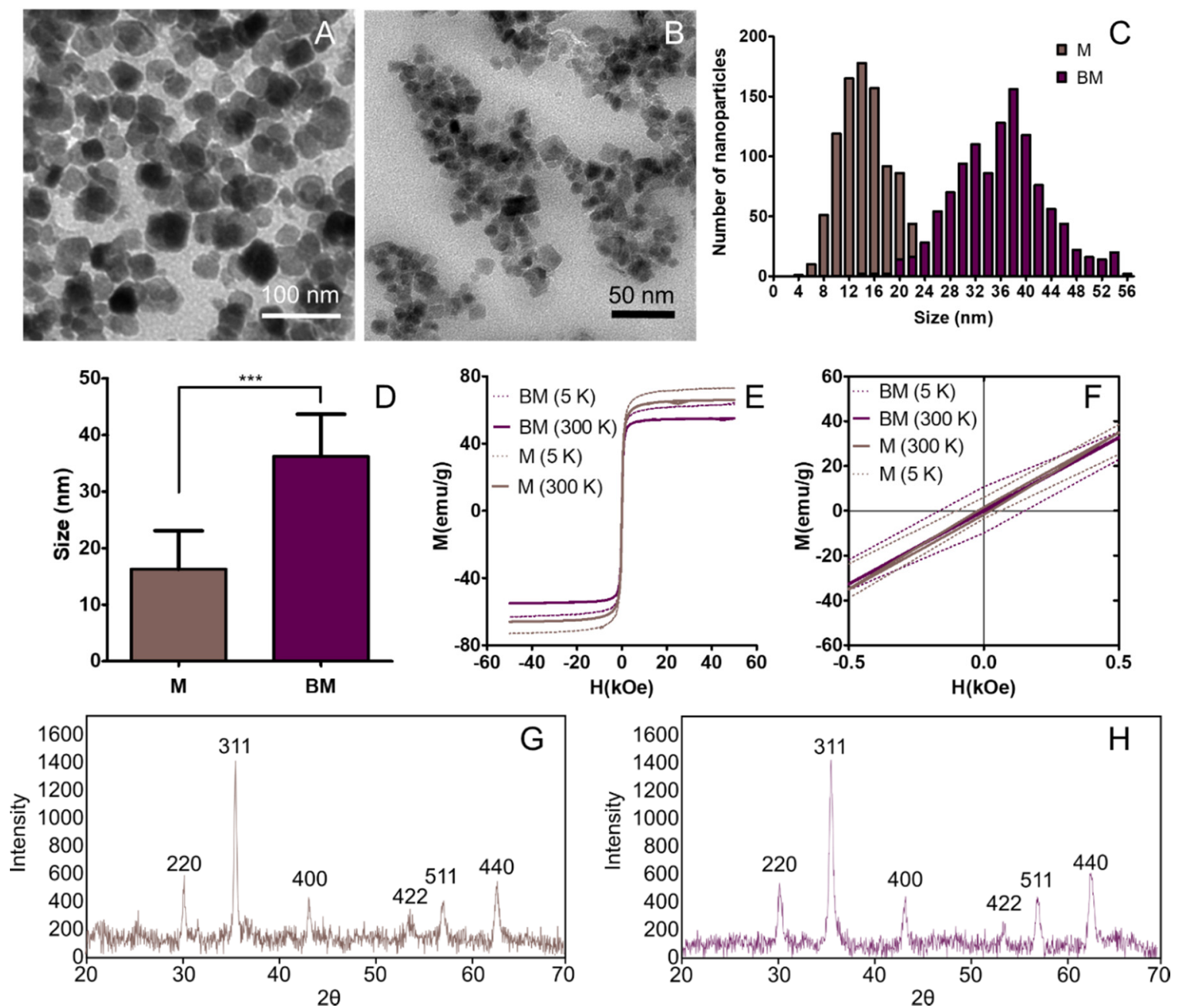

Figure 1. TEM images of biomimetic (A) and inorganic (B) magnetic nanoparticles. Diameter histograms of biomimetic and inorganic magnetic nanoparticles (C). Mean \pm standard deviation of nanoparticles size (D) $p<0.001{ }^{(* * *)}$. Hysteresis loop of BM and M (E,F: detail). X-ray diffraction (XRD) of M (G) and $\mathrm{BM}(\mathbf{H})$.

The $\zeta$ potential values for $\mathrm{BM}$ and $\mathrm{M}$ reveal that both nanoparticles display different charge at physiological $\mathrm{pH}$ (Figure 2A). While $\mathrm{M}$ are neutral, $\mathrm{BM}$ are negatively charged $(-20 \mathrm{mV})$, which facilities their functionalization with the relevant molecule at this physiological $\mathrm{pH}$ value mediated by electrostatic interactions. The BM used in this work were functionalized with DOXO and with the AR-3 mAb. This antibody, an IgG1, was chosen as a ligand model, since it reacts with a biomarker specifically expressed on different types of carcinomas, in particular those of the gastro-enteric tract, and in particular with a carbohydrate epitope present on a high molecular weight mucin $[25,26]$. The ability of these nanoparticles to be easily functionalized is conferred by the MamC protein. As shown in Figure 2A, at the $\mathrm{pH}$ value at which $\mathrm{BM}$ functionalization was carried out ( $\mathrm{pH}$ value of 7.4), $\mathrm{BM}$ had a $\zeta$-potential value of about $-20 \mathrm{mV}$, and therefore they were negatively charged. At this $\mathrm{pH}$ value, the monoclonal antibody is slightly positively charged and DOXO is also positively charged due to $-\mathrm{NH}_{3}{ }^{+}$groups exposed in aqueous solution, thus allowing the coupling of these two molecules to the BM based on electrostatic interactions. Identical behaviour was shown when these $\mathrm{BM}$ were functionalized with the monoclonal antibody DO-24 [22]. This is the great advantage of these BMs, which do not need further coating with other molecules that could alter the nanoparticles or their performance in biological systems, as previously shown by the covering of nanoparticles with AMPTES [31]. The coupling of DOXO and of the antibody to the BMs was extensively characterized by 
Peigneux et al. [22] (both the kinetics and thermodynamics of the coupling process and the structure and functionality of the relevant molecules after coupling), which shows that, under the conditions of the experiment, $\sim 50 \%$ of the initial $\mathrm{mAb}$ in solution were first adsorbed on the $\mathrm{BM}$ and, after further coupling with DOXO, $\sim 80 \%$ of the initial DOXO in solution was adsorbed at the plateau. As shown in Figure 2, the coupling of BM with DOXO and with the AR-3 mAb changes the surface properties of the nanoformulation. In fact, the $\zeta$ potential values for TBM are similar to those exposed by $\mathrm{M}$ nanoparticles, i.e., neutral a physiological $\mathrm{pH}$. This result indicates that the negatively charged functional groups that MamC was previously exposing are now masked by DOXO and by AR-3 mAb. This functionalization is further confirmed by FT-IR analysis. The FR-IR spectra of TBM (Figure 2B) shows absorption peaks characteristics of bonds present in the different elements that constitute the TBM nanoparticles. The sample show signals at 3200, 2890, 1585, 1282, 114, 1070, and $988 \mathrm{~cm}^{-1}$ (marked in red), which are characteristics of the DOXO molecule [32]. On the other hand, the spectra show the relevant absorption peaks associated with the Amide I $\left(1658 \mathrm{~cm}^{-1}\right)$, II $\left(1538 \mathrm{~cm}^{-1}\right)$, and III $\left(1242 \mathrm{~cm}^{-1}\right)$ (marked in green), characteristics of $\mathrm{mAb}[33,34]$. Finally, a new peak at $542 \mathrm{~cm}^{-1}$ characteristic of the Fe-O bond in magnetite is observed [35].

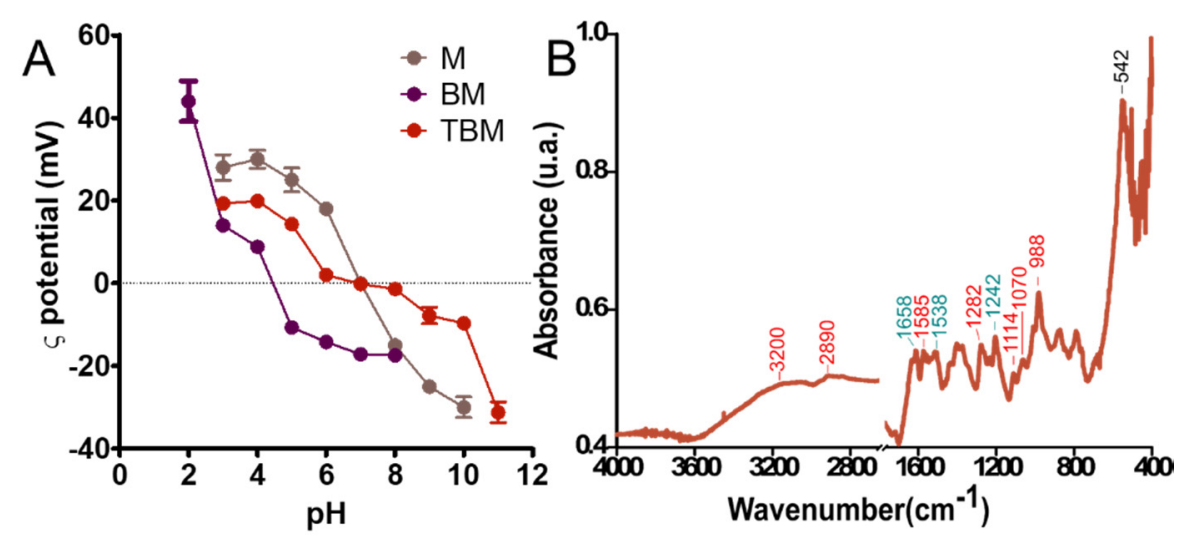

Figure 2. $\zeta$ potential of M, BM and TBM (A). ATR-FTIR spectra of TBM (B). The signal corresponding to different elements are marked in red (DOXO), green (AR-3 mAb) and black (magnetite).

\subsection{Magnetic Hyperthermia Responses}

In terms of how these $\mathrm{M}$ and TBM behave upon the application of an alternating magnetic field, Figure 3 shows that they both are able to increase the temperature in a frequency dependent way, the higher increase corresponding to the higher frequencies. Comparing the data of the TBM from the present paper to those of BM already published by Peigneux et al. [22] and Iglesias et al., [23], it can be concluded that the presence of the molecules adsorbed to the BM does not interfere significantly with the ability of TBM to respond to an alternating magnetic field. However, data in Figure 3 and Table 1 show that M display a better behavior compared to BM and TBM in producing hyperthermia [23], which might be depended on their higher relation in magnetic/non-magnetic material compared to BM and TBM, as also observed for other encapsulated magnetic nanoparticles [6,36]. 

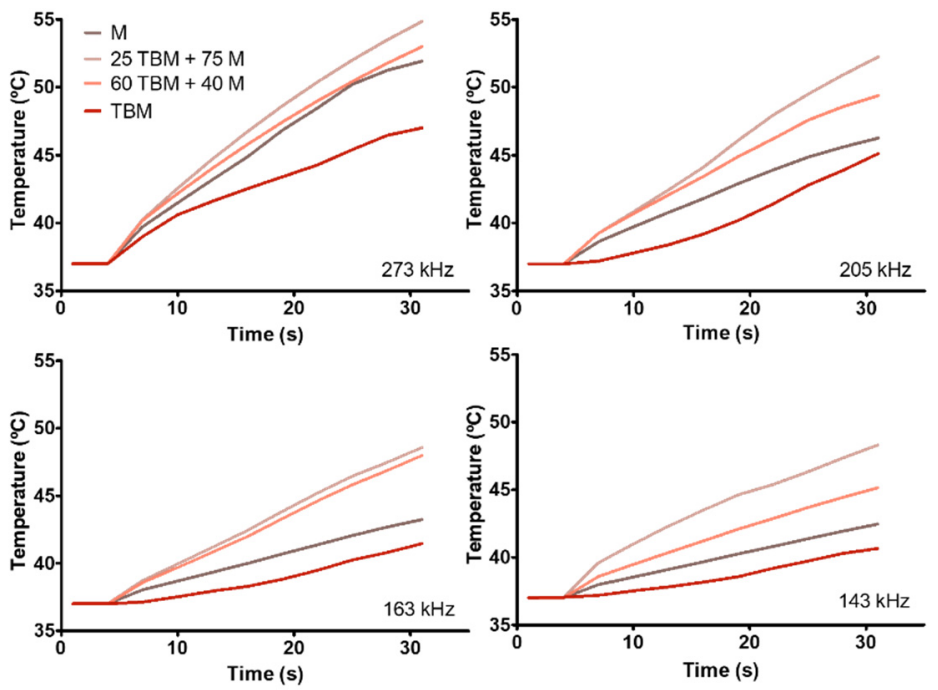

Figure 3. Time evolution of the temperature of the different nanoparticles suspensions, for different frequencies. Magnetic field strength: $\mathrm{H}_{0}=12.5 \mathrm{kA} / \mathrm{m}$. Sample volume $0.5 \mathrm{~mL}$; particle concentration: $30 \mathrm{mg} / \mathrm{mL}$.

Table 1. Summary of SAR and ILP calculations at different frequencies with a fixed magnetic field intensity of $12.5 \mathrm{kA} / \mathrm{m}$.

\begin{tabular}{|c|c|c|c|c|}
\hline System & $\begin{array}{c}\text { Frequency } f \\
{[\mathbf{k H z}]}\end{array}$ & $\begin{array}{l}\text { SAR } \\
{[W / g]}\end{array}$ & $\begin{array}{c}\text { Slope dT/dt } \\
{\left[{ }^{\circ} \mathrm{C} / \mathrm{s}\right]}\end{array}$ & $\begin{array}{c}\text { ILP } \\
{\left[\mathrm{nHm}^{2} \mathrm{~kg}^{-1}\right]}\end{array}$ \\
\hline \multirow{4}{*}{ M } & $273 \pm 5$ & $68 \pm 4$ & $0.50 \pm 0.02$ & $1.6 \pm 0.1$ \\
\hline & $205 \pm 5$ & $47 \pm 2$ & $0.345 \pm 0.009$ & $1.34 \pm 0.08$ \\
\hline & $163 \pm 5$ & $28 \pm 1$ & $0.202 \pm 0.005$ & $1.12 \pm 0.06$ \\
\hline & $143 \pm 5$ & $24 \pm 1$ & $0.175 \pm 0.004$ & $1.09 \pm 0.06$ \\
\hline \multirow{4}{*}{$25 \mathrm{TBM}+75 \mathrm{M}$} & $273 \pm 5$ & $86 \pm 4$ & $0.58 \pm 0.02$ & $2.1 \pm 0.1$ \\
\hline & $205 \pm 5$ & $73 \pm 4$ & $0.50 \pm 0.01$ & $2.3 \pm 0.1$ \\
\hline & $163 \pm 5$ & $54 \pm 3$ & $0.379 \pm 0.009$ & $2.1 \pm 0.1$ \\
\hline & $143 \pm 5$ & $47 \pm 3$ & $0.36 \pm 0.02$ & $2.1 \pm 0.2$ \\
\hline \multirow{4}{*}{$60 \mathrm{TBM}+40 \mathrm{M}$} & $273 \pm 5$ & $69 \pm 5$ & $0.51 \pm 0.02$ & $1.6 \pm 0.1$ \\
\hline & $205 \pm 5$ & $56 \pm 3$ & $0.41 \pm 0.01$ & $1.8 \pm 0.1$ \\
\hline & $163 \pm 5$ & $44 \pm 3$ & $0.350 \pm 0.009$ & $1.7 \pm 0.1$ \\
\hline & $143 \pm 5$ & $36 \pm 2$ & $0.262 \pm 0.007$ & $1.66 \pm 0.09$ \\
\hline \multirow{4}{*}{ TBM } & $273 \pm 5$ & $53 \pm 3$ & $0.37 \pm 0.02$ & $1.23 \pm 0.07$ \\
\hline & $205 \pm 5$ & $41 \pm 2$ & $0.27 \pm 0.02$ & $1.17 \pm 0.08$ \\
\hline & $163 \pm 5$ & $22 \pm 1$ & $0.162 \pm 0.009$ & $0.88 \pm 0.05$ \\
\hline & $143 \pm 5$ & $19 \pm 1$ & $0.134 \pm 0.007$ & $0.84 \pm 0.04$ \\
\hline
\end{tabular}

Interestingly, when these two systems are combined, the temperature increase is higher compared to that of the endmembers, being the nanoformulation $25 \mathrm{TBM}+75 \mathrm{M}$ the one that induce the higher temperature increase. In all cases, the temperature needed to induce apoptosis in tumor cells $\left(42-46^{\circ} \mathrm{C}[7,37]\right)$ is reached in a few seconds $(\sim 30 \mathrm{~s})$ under an alternating magnetic field of $12.5 \mathrm{kA} / \mathrm{m}$. The SAR and ILP values are represented in Figure 4 (Table 1) and are in agreement with the results obtained in [23]. 

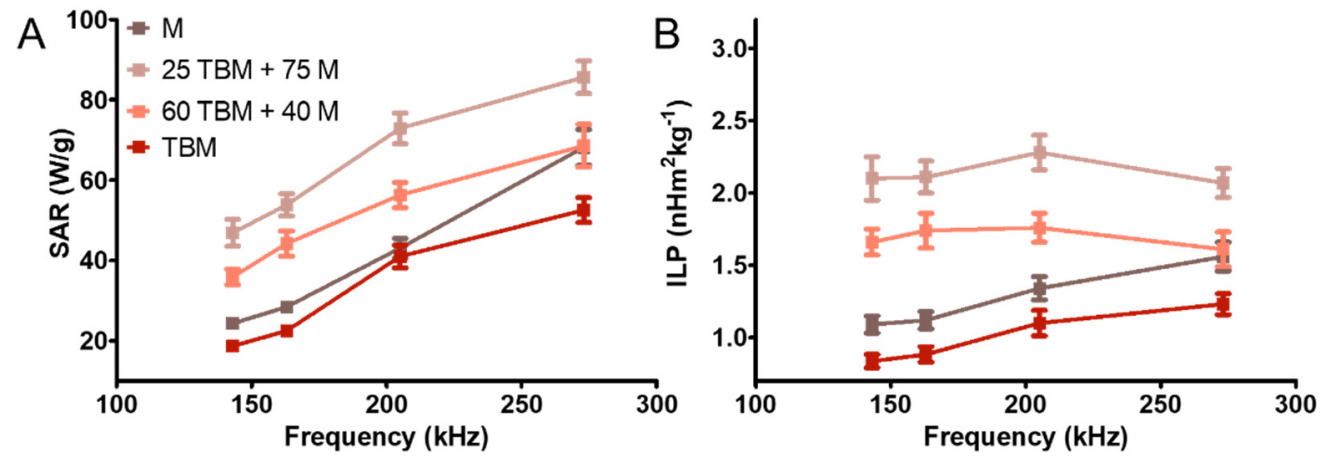

Figure 4. Frequency dependence of SAR (A) and ILP (B) for the different nanoparticles suspension. Magnetic field strength: $12.5 \mathrm{kA} / \mathrm{m}$; particle concentration: $30 \mathrm{mg} / \mathrm{mL}$.

\subsection{Colloidal Stability}

Colloidal stability against agglomeration and sedimentation is one of the main requirements for biomedical applications of nanoparticles, this stability being influenced by different factors such as volume fraction, size distribution and temperature [38]. In general, to avoid aggregation and precipitation, the nanoparticles need to be further coated with a long chain polymer. This coating is not necessary in our BM nanoparticles due to the presence of MamC. However, the larger sizes of BM and TBM compared to that of M could affect their colloidal stability. The colloidal stability analysis shown in Figure 5A (Figure S1) reveals that the 25 TBM $+75 \mathrm{M}$ sample shows the highest stability, similar to that exhibited by $\mathrm{M}$, followed in decreasing order by $60 \mathrm{TBM}+40 \mathrm{M}$ and TBM samples. This fact could probably be the result of a stabilizing effect mediated by the interaction of the smaller M size with the TBM coating [23]. Smaller M nanoparticles could intercalate within the TBM nanoassemblies and potentiate the electrostatic repulsion being both negatively charged at physiological $\mathrm{pH}$ values $(\mathrm{pH}=7.4, \mathrm{M}-7.5 \mathrm{mV}$ and $\mathrm{TBM}-1.4 \mathrm{mV})$. The smaller the amount of $\mathrm{M}$, the lower this electrostatic repulsion is and the slight charge of TBM at physiological $\mathrm{pH}$ values may not be enough to force electrostatic repulsion between nanoassemblies, with TBM thus being prone to agglomeration. These results are in agreement with the hydrodynamic radius data (Figure 5B). Dynamic light scattering (DLS) analysis show that the hydrodynamic diameters of the M, $25 \mathrm{TBM}+$ $75 \mathrm{M}, 60 \mathrm{TBM}+40 \mathrm{M}$ and TBM are of $700 \pm 100 \mathrm{~nm}, 900 \pm 100 \mathrm{~nm}, 1200 \pm 100 \mathrm{~nm}$, and $1300 \pm 100 \mathrm{~nm}$, respectively. The polydispersity index (PDI) of these samples are $0.249 \pm 0.004,0.214 \pm 0.008,0.283 \pm$ 0.001 , and $0.285 \pm 0.002$, respectively.
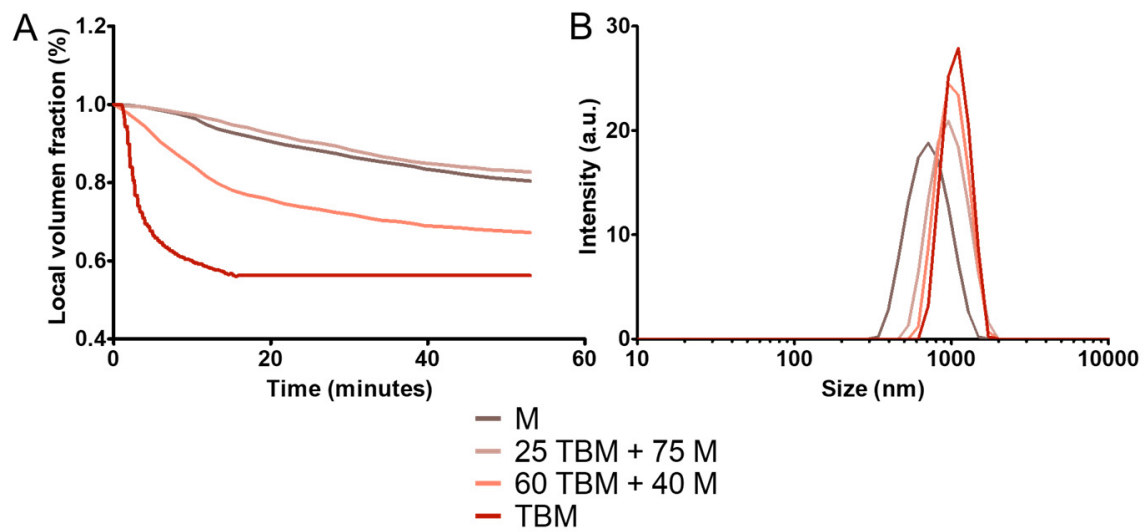

Figure 5. Colloidal stability of M, $25 \mathrm{TBM}+75 \mathrm{M}$ and $60 \mathrm{TBM}+40 \mathrm{M}$. Height normalized to its initial volume value as a function of time (A). Hydrodynamic size in intensity distribution for the different formulations (B). 
Previous studies have demonstrated that $\mathrm{M}$ display better magnetic hyperthermia response than BM and TBM (as shown in Figure 3 and Table 1), due to the difficulty for rotation conditioned by the MamC protein coating and their larger size $[20,23,39]$. However, the combination of M and TBM yielded the highest values for the hyperthermia analyses. In fact, the maximum SAR and ILP values were obtained by $25 \mathrm{TBM}+75 \mathrm{M}$ system, followed by $60 \mathrm{TBM}+40 \mathrm{M}, \mathrm{M}$ and TBM (Table 1, Figure 4). These increased SAR and ILP values could be explained by the higher colloidal stability of the 25 $\mathrm{TBM}+75 \mathrm{M}$ system compared to that of the $60 \mathrm{TBM}+40 \mathrm{M}$ (Figure 5), since aggregation negatively affects the rotation of the nanoparticles under the influence of the AMF, and thus the temperature rise. Moreover, suspensions of nanoparticles with broad size distributions have been proposed to yield an optimized magnetic hyperthermia response, since, in this case, the probability that a percentage of the nanoparticles in the system are always rotating in response to a given AMF is maximized [28]. This would apply to our mixed system, which combines magnetic nanoparticles with sizes up to 70 $\mathrm{nm}$, showing a broader size distribution compared to that of the end members (up to $30 \mathrm{~nm}$ in $\mathrm{M}$ and up to $70 \mathrm{~nm}$ in TBM; Figure 1). In consequence, a higher percentage of the nanoparticles are likely to be affected by the influence of the magnetic field in the mixture compared to that in the end members, thus resulting in a more efficient temperature rise produced by the former.

\subsection{Nanoformulation as DOXO Nanocarrier. Synergy of Magnetic Hyperthermia and of $p H$ Decrease in the Drug Release}

When the mixture of $25 \mathrm{TBM}+75 \mathrm{M}$ was incubated up to $75 \mathrm{~min}$ at a $\mathrm{pH}$ value of 7.4 (physiological $\mathrm{pH}$ value), less than $2 \%$ of the adsorbed DOXO was released from TBM (Figure 6), thus indicating the stability of the nanoformulation at physiological $\mathrm{pH}$ values. However, when the nanoformulation was incubated in an acidic environment mimicking the one in the endosomal/lysosomal compartment ( $\mathrm{pH}$ 5.0) the release of DOXO increased to more than $25 \%$, and this value was further increased to $44 \%$ when an AMF treatment $(\mathrm{H}=20 \mathrm{kA} / \mathrm{m}, f=130 \mathrm{kHz})$ for 30 min was applied. This synergy between acidic $\mathrm{pH}$ and AMF on the release of the DOXO coupled to MamC-mediated BM was previously reported by Peigneux et al. [22]. These authors showed that the electrostatic bond, which at higher $\mathrm{pH}$ values kept DOXO bound to the surface of the nanoparticles, weakens as BM approach their iep (4.4), thus triggering DOXO release. Following application of the AMF, the kinetics of DOXO release is probably faster because of the heating of the BM surface [22]. However, this heating is not enough to break the electrostatic bond that keeps DOXO attached to the nanoparticle at physiological $\mathrm{pH}$ values (DOXO release increases from $2 \%$ to $5 \%$ after the application of AMF), while, at acidic $\mathrm{pH}$ values, it is enough to break the electrostatic bond once the BM surface is no longer so negative. The enhancing effect of drug release induced by magnetic hyperthermia was pointed out by other authors, using different drugs and magnetic nanocarriers $[8,40,41]$. This synergy further confirms our hypothesis that the effectiveness of the treatment could be increased by combining the two therapies of drug delivery and hyperthermia by using this multifunctional nanoformulation, which moreover allows a dual tumor targeting (magnetic field and monoclonal antibody).

\subsection{Cytotoxicity Evaluation}

The toxic activity of the different nanoformulations (25 BM + $75 \mathrm{M}$ and $25 \mathrm{TBM}+75 \mathrm{M})$, and their respective components, were assessed in an MTT assay carried out on the colon carcinoma HT-29 cell line, which express the AR-3 mAb-defined biomarker, after $72 \mathrm{~h}$ of treatment. Soluble DOXO was used at the same concentrations as that contained in the nanoformulations, as positive control. Figure 7A shows the cell viability compared to that of the untreated controls (CTRL-). As previously shown by our groups [20,22,30,42], BM are cytocompatible. Indeed, both M and DOXO-free $25 \mathrm{BM}+$ $75 \mathrm{M}$ nanoformulations display low cytotoxicity, and in all cases cell viability is above $80 \%$, which is considered the cut-off indicated by ISO 10993-5:2009 [43]. By contrast, TBM and the 25 TBM $+75 \mathrm{M}$ mixture display a significant toxicity. In particular, for higher doses of DOXO $\left(\mathrm{DOXO}^{1}\right)$, as in the case of TBM, no differences were observed in respect to soluble DOXO, while for lower doses of DOXO 
(around $\left.\frac{1}{4}\right)$, as in the case of $25 \mathrm{TBM}+75 \mathrm{M}$, the soluble DOXO $\left(\mathrm{DOXO}^{2}\right)$ was more efficient than the DOXO coupled to TBM. Similar findings have already been reported, both for MNPs $[22,44]$ and for other functionalized inorganic NPs [27,45], and are explained by the fact that soluble DOXO can more easily diffuse through the cell membrane.

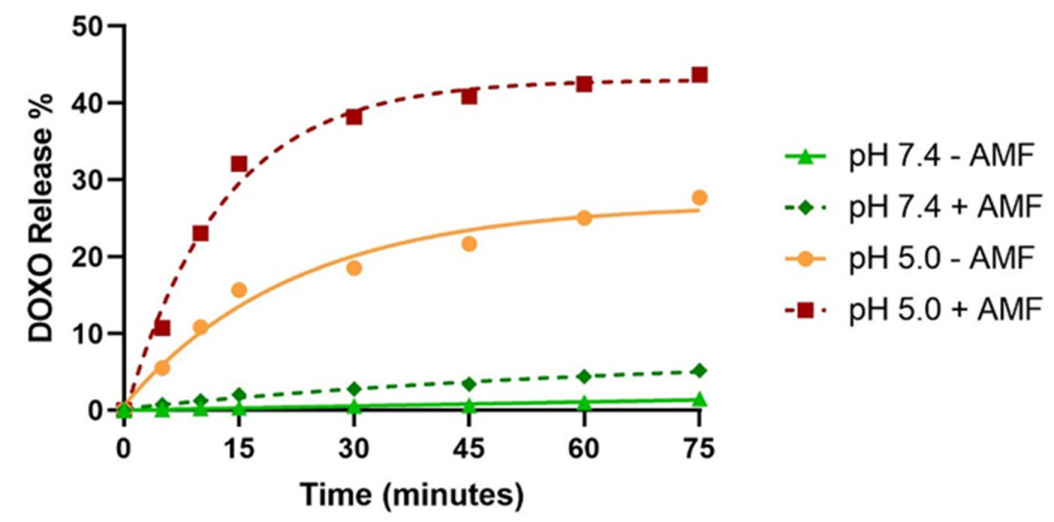

Figure 6. DOXO release percentage as a function of time measured with and without (AMF) at different pHs (7.4 and 5.0). The vertical error bars are smaller than the symbol.
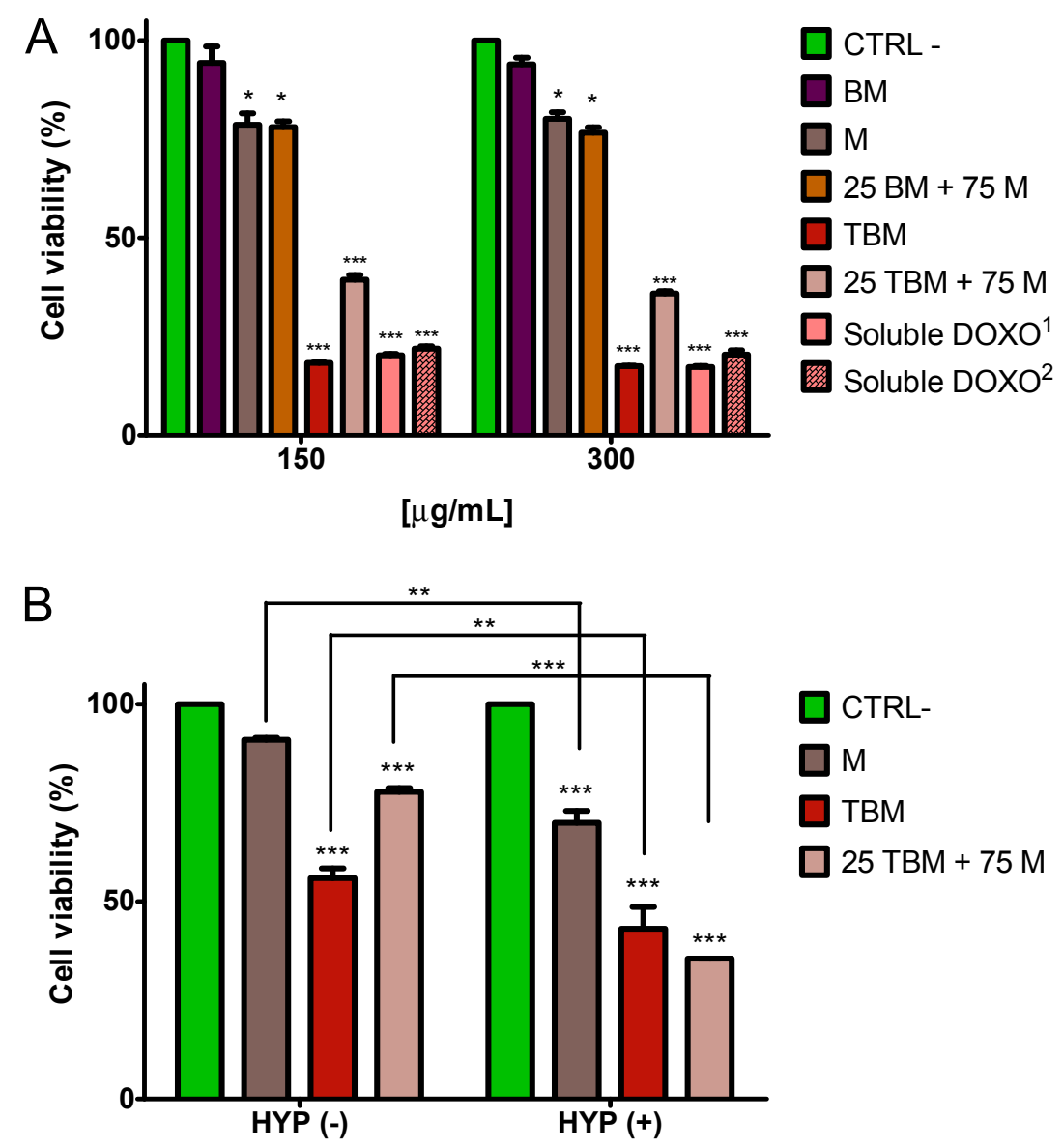

Figure 7. Cytotoxicity of the differentially functionalized nanoassemblies on HT-29 cells measured in MTT assay after $72 \mathrm{~h}$ without AMF (A) and during $24 \mathrm{~h}$ with AMF (B). Soluble DOXO ${ }^{1}(36 \mu \mathrm{g} / \mathrm{mL})$ corresponds to the equimolar amount of drug loaded on TBM sample. Soluble DOXO $2(9 \mu \mathrm{g} / \mathrm{mL})$ corresponds to the equimolar amount of drug loaded on 25 TBM + 75 M sample. Control cells (CTRL-) not incubated with nanoparticles or DOXO were taken as reference value $(100 \%)$ of viable cells to which refer the values of treated cells. $\left.\left.p \leq 0.05\left(^{*}\right), p \leq 0.01{ }^{* *}\right), p \leq 0.001{ }^{(* *}\right)$. 
When cells were exposed to AMF for $2 \mathrm{~h}$ after $24 \mathrm{~h}$ of incubation with M, TBM, and DOXO nanoassemblies $(25 \mathrm{TBM}+75 \mathrm{M})$, it was observed that, under all experimental conditions, the application of AMF significantly reduced cell viability in respect to control cells incubated in the absence of magnetic nanoparticles. Moreover, despite the fact that TBM has a higher DOXO load than the $25 \mathrm{TBM}+75 \mathrm{M}$ nanoformulation, the decrease in cell viability was more evident when cells were incubated with the latter formulation, an effect that may be due to the higher hyperthermia caused by $25 \mathrm{TBM}+75 \mathrm{M}$ nanoformulation (Figure 7B). These data suggest that a significant level of cytotoxicity can be also reached or even improved with a lower amount of drug by using a mixture of magnetic nanoparticles that increases the hyperthermia response.

\section{Conclusions}

Results from the present study show that the nanoformulation here proposed, integrated by a combination of two different types of magnetic nanoparticles, one inorganic with an average size of $\sim 15 \mathrm{~nm}$, and the other biomimetic (mediated by the magnetosome associated protein MamC) with an average size of $\sim 36 \mathrm{~nm}$, can be used as a multifunctional platform for a combined therapy. Indeed, the inorganic nanoparticles show good potential as magnetic hyperthermia agents, while the biomimetic nanoparticles are better suitable as nanocarrier, being able to be functionalized with a drug and a targeting probe by electrostatic interaction, being the release of the drug $\mathrm{pH}$ dependent. Both particles are superparamagnetic and are able to respond to a continuous gradient field used for guiding them at the target site. The mixture of the two types of nanoparticles overcome the already good potential demonstrated for the pure end members, in terms of colloidal stability and magnetic hyperthermia response. Moreover, it allows a synergy between drug delivery and magnetic hyperthermia that increases the release of the relevant drug at acidic conditions mimicking tumor sites. Thus, this multifunctional combined platform could reach the target site by the application of dual guidance (external magnetic field and active targeting antibody), and could act as an anti-tumor agent in a bimodal way: by hyperthermia upon the application of an alternated magnetic field and by carrying and releasing the drug in $\mathrm{pH}$ - and temperature-dependent manners. Data from the present study may help in optimizing new treatments in which cytotoxicity is raised not by increasing the dose of the chemotherapeutic agent, but by the simultaneous use of magnetic hyperthermia.

Supplementary Materials: The following are available online at http://www.mdpi.com/2073-4360/12/8/1832/s1, Figure S1. Colloidal stability video of the samples measured using photograms of the sedimentation time evolution.

Author Contributions: Conceptualization, G.R.I., M.P., and C.J.-L.; methodology and investigation, Y.J., F.O., G.R.I., A.P., A.S.-L., and M.P.C.-J.; writing-original draft preparation, Y.J. and F.O.; writing—review and editing, Y.J., F.O., G.R.I., M.P., and C.J.-L.; supervision, M.P. and C.J.-L.; funding acquisition, G.R.I., M.P., and C.J.-L. All authors have read and agreed to the published version of the manuscript.

Funding: G.R.I. wish to thank project RYC-2014-6901 (MINECO, Spain), Programa Operativo FEDER 2014-2020 (A1-FQM-341-UGR18, C-FQM-497-UGR18) Junta de Andalucia. C.J.-L. wants to thank projects CGL2016-76723 from the Ministerio de Economía y Competitividad from Spain and Fondo Europeo de Desarrollo Regional (FEDER) and Programa Operativo FEDER 2014-2020 (A-BIO-376-UGR18) Junta de Andalucia. M.P. was suppported by Progetto di Ricerca Fondi di Ateneo per la Ricerca-FAR 2017 "Development of innovative biological materials for the functional regeneration of cardiac tissue models". Y.J. wants to acknowledge a FPU2016 grant (ref. FPU16_04580) from the Ministerio de Educación, Ciencia y Deporte y Competitividad (Spain). F.O. has received funding from the European Union's Horizon 2020 research and innovation programme under the Marie Skłodowska-Curie grant agreement $N^{\circ} 754446$ and UGR Research and Knowledge Transfer Found-Athenea3i. A.S.-L. is funded by the Spanish Ministry of Science, Innovation and Universities (PRE2018-0854409).

Acknowledgments: Thanks go to the Scientific Instrumentation Center (CIC) personnel of the University of Granada for technical assistance with the TEM.

Conflicts of Interest: The authors declare no conflict of interest. 


\section{References}

1. Yagawa, Y.; Tanigawa, K.; Kobayashi, Y.; Yamamoto, M. Cancer immunity and therapy using hyperthermia with immunotherapy, radiotherapy, chemotherapy, and surgery. J. Cancer Metastasis Treat. 2017, 3, 218. [CrossRef]

2. Phung, D.C.; Nguyen, H.T.; Phuong Tran, T.T.; Jin, S.G.; Yong, C.S.; Truong, D.H.; Tran, T.H.; Kim, J.O. Combined hyperthermia and chemotherapy as a synergistic anticancer treatment. J. Pharm. Investig. 2019, 49, 519-526. [CrossRef]

3. Garanina, A.S.; Naumenko, V.A.; Nikitin, A.A.; Myrovali, E.; Petukhova, A.Y.; Klimyuk, S.V.; Nalench, Y.A.; Ilyasov, A.R.; Vodopyanov, S.S.; Erofeev, A.S.; et al. Temperature-controlled magnetic nanoparticles hyperthermia inhibits primary tumor growth and metastases dissemination. Nanomed. Nanotechnol. Biol. Med. 2020, 25, 102171. [CrossRef]

4. Liu, X.; Zhang, Y.; Wang, Y.; Zhu, W.; Li, G.; Ma, X.; Zhang, Y.; Chen, S.; Tiwari, S.; Shi, K.; et al. Comprehensive understanding of magnetic hyperthermia for improving antitumor therapeutic efficacy. Theranostics 2020, 10, 3793-3815. [CrossRef]

5. Kang, J.K.; Kim, J.C.; Shin, Y.; Han, S.M.; Won, W.R.; Her, J.; Park, J.Y.; Oh, K.T. Principles and applications of nanomaterial-based hyperthermia in cancer therapy. Arch. Pharm. Res. 2020, 43, 46-57. [CrossRef]

6. Häring, M.; Schiller, J.; Mayr, J.; Grijalvo, S.; Eritja, R.; Díaz, D. Magnetic Gel Composites for Hyperthermia Cancer Therapy. Gels 2015, 1, 135-161. [CrossRef]

7. Reddy, L.H.; Arias, J.L.; Nicolas, J.; Couvreur, P. Magnetic nanoparticles: Design and characterization, toxicity and biocompatibility, pharmaceutical and biomedical applications. Chem. Rev. 2012, 112, 5818-5878. [CrossRef]

8. Iglesias, G.R.; Reyes-Ortega, F.; Fernandez, B.L.C.; Delgado, Á.V. Hyperthermia-triggered gemcitabine release from polymer-coated magnetite nanoparticles. Polymers 2018, 10, 269. [CrossRef]

9. Husain, Q. Magnetic nanoparticles as a tool for the immobilization/stabilization of hydrolases and their applications: An overview. Appl. Chem. 2016, 6, 1585-1606.

10. Mehdaoui, B.; Meffre, A.; Carrey, J.; Lachaize, S.; Lacroix, L.-M.; Gougeon, M.; Chaudret, B.; Respaud, M. Optimal Size of Nanoparticles for Magnetic Hyperthermia: A Combined Theoretical and Experimental Study. Adv. Funct. Mater. 2011, 21, 4573-4581. [CrossRef]

11. Mohapatra, J.; Zeng, F.; Elkins, K.; Xing, M.; Ghimire, M.; Yoon, S.; Mishra, S.R.; Liu, J.P. Size-dependent magnetic and inductive heating properties of $\mathrm{Fe}_{3} \mathrm{O}_{4}$ nanoparticles: Scaling laws across the superparamagnetic size. Phys. Chem. Chem. Phys. 2018, 20, 12879-12887. [CrossRef]

12. Briceno, S.; Silva, P.; Bramer-Escamilla, W.; Zabala, J.; Alcala, O.; Guari, Y.; Larionova, J.; Long, J.; Briceño, S.; Long, J. Magnetic water-soluble rhamnose-coated Mn1-xCoxFe2O4 nanoparticles as potential heating agents for hyperthermia. Biointerface Res. Appl. Chem. 2015, 5, 910-915.

13. Yüksel, Y. Effects of the particle size and shape of the magnetic nanoparticles on the magnetic hyperthermia and exchange bias properties. Phys. B Condens. Matter 2019, 575, 411689. [CrossRef]

14. Jabalera, Y.; Fernández-Vivas, A.; Iglesias, G.R.; Delgado, Á.V.; Jimenez-Lopez, C. Magnetoliposomes of mixed biomimetic and inorganic magnetic nanoparticles as enhanced hyperthermia agents. Colloids Surf. B Biointerfaces 2019, 183, 110435. [CrossRef]

15. Li, Z.; Kawashita, M.; Araki, N.; Mitsumori, M.; Hiraoka, M.; Doi, M. Magnetite nanoparticles with high heating efficiencies for application in the hyperthermia of cancer. Mater. Sci. Eng. C 2010, 30, 990-996. [CrossRef]

16. Li, Q.; Kartikowati, C.W.; Horie, S.; Ogi, T.; Iwaki, T.; Okuyama, K. Correlation between particle size/domain structure and magnetic properties of highly crystalline $\mathrm{Fe}_{3} \mathrm{O}_{4}$ nanoparticles. Sci. Rep. 2017, 7, 9894. [CrossRef]

17. Arruebo, M.; Fernández-Pacheco, R.; Ibarra, M.R.; Santamaría, J. Magnetic nanoparticles for drug delivery. Nano Today 2007, 2, 22-32. [CrossRef]

18. El-Boubbou, K. Magnetic iron oxide nanoparticles as drug carriers: Preparation, conjugation and delivery. Nanomedicine 2018, 13, 929-952. [CrossRef] 
19. Valverde-Tercedor, C.; Montalbán-López, M.; Perez-Gonzalez, T.; Sanchez-Quesada, M.S.; Prozorov, T.; Pineda-Molina, E.; Fernandez-Vivas, M.A.; Rodriguez-Navarro, A.B.; Trubitsyn, D.; Bazylinski, D.A.; et al. Size control of in vitro synthesized magnetite crystals by the MamC protein of Magnetococcus marinus strain MC-1. Appl. Microbiol. Biotechnol. 2015, 99, 5109-5121. [CrossRef]

20. García Rubia, G.; Peigneux, A.; Jabalera, Y.; Puerma, J.; Oltolina, F.; Elert, K.; Colangelo, D.; Gómez Morales, J.; Prat, M.; Jimenez-Lopez, C. PH-Dependent Adsorption Release of Doxorubicin on MamC-Biomimetic Magnetite Nanoparticles. Langmuir 2018, 34, 13713-13724. [CrossRef]

21. Jabalera, Y.; Garcia-Pinel, B.; Ortiz, R.; Iglesias, G.; Cabeza, L.; Prados, J.; Jimenez-Lopez, C.; Melguizo, C. Oxaliplatin-Biomimetic Magnetic Nanoparticle Assemblies for Colon Cancer-Targeted Chemotherapy: An In Vitro Study. Pharmaceutics 2019, 11, 395. [CrossRef]

22. Iglesias, G.R.; Jabalera, Y.; Peigneux, A.; Checa Fernández, B.L.; Delgado, Á.V.; Jimenez-Lopez, C.; Iglesias, G.R.; Jabalera, Y.; Peigneux, A.; Checa Fernández, B.L.; et al. Enhancement of Magnetic Hyperthermia by Mixing Synthetic Inorganic and Biomimetic Magnetic Nanoparticles. Pharmaceutics 2019, 11, 273. [CrossRef]

23. Perez-Gonzalez, T.; Jimenez-Lopez, C.; Neal, A.L.; Rull-Perez, F.; Rodriguez-Navarro, A.; Fernandez-Vivas, A.; Iañez-Pareja, E. Magnetite biomineralization induced by Shewanella oneidensis. Geochim. Cosmochim. Acta 2010, 74, 967-979. [CrossRef]

24. Prat, M.; Morra, I.; Bussolati, G.; Comoglio, P.M. CAR-3, a monoclonal antibody-defined antigen expressed on human carcinomas. Cancer Res. 1985, 45, 5799-5807.

25. Prat, M.; Medico, E.; Rossino, P.; Garrino, C.; Comoglio, P.M. Biochemical and immunological properties of the human carcinoma-associated CAR-3 epitope defined by the monoclonal antibody AR-3. Cancer Res. 1989, 49, 1415-1421.

26. Iafisco, M.; Delgado-Lopez, J.M.; Varoni, E.M.; Tampieri, A.; Rimondini, L.; Gomez-Morales, J.; Prat, M. Cell Surface Receptor Targeted Biomimetic Apatite Nanocrystals for Cancer Therapy. Small 2013, 9, 3834-3844. [CrossRef]

27. Obaidat, I.; Issa, B.; Haik, Y. Magnetic Properties of Magnetic Nanoparticles for Efficient Hyperthermia. Nanomaterials 2015, 5, 63-89. [CrossRef]

28. Wildeboer, R.R.; Southern, P.; Pankhurst, Q.A. On the reliable measurement of specific absorption rates and intrinsic loss parameters in magnetic hyperthermia materials. J. Phys. D. Appl. Phys. 2014, 47, 495003. [CrossRef]

29. Peigneux, A.; Oltolina, F.; Colangelo, D.; Iglesias, G.R.; Delgado, A.V.; Prat, M.; Jimenez-Lopez, C. Functionalized Biomimetic Magnetic Nanoparticles as Effective Nanocarriers for Targeted Chemotherapy. Part. Part. Syst. Charact. 2019, 36, 1900057. [CrossRef]

30. Jabalera, Y.; Sola-Leyva, A.; Peigneux, A.; Vurro, F.; Iglesias, G.R.; Vilchez-Garcia, J.; Pérez-Prieto, I.; Aguilar-Troyano, F.J.; López-Cara, L.C.; Carrasco-Jiménez, M.P.; et al. Biomimetic magnetic nanocarriers drive choline kinase alpha inhibitor inside cancer cells for combined chemo-hyperthermia therapy. Pharmaceutics 2019, 11, 408. [CrossRef]

31. Oltolina, F.; Gregoletto, L.; Colangelo, D.; Gómez-Morales, J.; Delgado-López, J.M.; Prat, M. Monoclonal antibody-targeted fluorescein-5-isothiocyanate-labeled biomimetic nanoapatites: A promising fluorescent probe for imaging applications. Langmuir 2015, 31, 1766-1775. [CrossRef] [PubMed]

32. Kanwal, U.; Bukhari, N.I.; Rana, N.F.; Rehman, M.; Hussain, K.; Abbas, N.; Mehmood, A.; Raza, A. Doxorubicin-loaded quaternary ammonium palmitoyl glycol chitosan polymeric nanoformulation: Uptake by cells and organs. Int. J. Nanomed. 2019, 14, 1-15. [CrossRef] [PubMed]

33. Yang, S.; Tse, W.H.; Zhang, J. Deposition of Antibody Modified Upconversion Nanoparticles on Glass by a Laser-Assisted Method to Improve the Performance of Cell Culture. Nanoscale Res. Lett. 2019, 14, 101. [CrossRef]

34. Glassford, S.E.; Byrne, B.; Kazarian, S.G. Recent applications of ATR FTIR spectroscopy and imaging to proteins. Biochim. Biophys. Acta Proteins Proteom. 2013, 1834, 2849-2858. [CrossRef]

35. Yang, S.; Zeng, T.; Li, Y.; Liu, J.; Chen, Q.; Zhou, J.; Ye, Y.; Tang, B. Preparation of Graphene Oxide Decorated $\mathrm{Fe}_{3} \mathrm{O}_{4} @ \mathrm{SiO}_{2}$ Nanocomposites with Superior Adsorption Capacity and SERS Detection for Organic Dyes. J. Nanomater. 2015, 2015, 817924. [CrossRef]

36. Zamora-Mora, V.; Soares, P.; Echeverria, C.; Hernández, R.; Mijangos, C. Composite Chitosan/Agarose Ferrogels for Potential Applications in Magnetic Hyperthermia. Gels 2015, 1, 69-80. [CrossRef] 
37. Huber, D.L. Synthesis, properties, and applications of iron nanoparticles. Small 2005, 1, 482-501. [CrossRef]

38. Sanz, B.; Calatayud, M.P.; Cassinelli, N.; Ibarra, M.R.; Goya, G.F. Long-Term Stability and Reproducibility of Magnetic Colloids Are Key Issues for Steady Values of Specific Power Absorption over Time. Eur. J. Inorg. Chem. 2015, 2015, 4524-4531. [CrossRef]

39. Nudelman, H.; Valverde-tercedor, C.; Kolusheva, S.; Perez, T.; Widdrat, M.; Grimberg, N.; Levi, H.; Nelkenbaum, O.; Davidov, G.; Faivre, D.; et al. Structure-function studies of the magnetite-biomineralizing magnetosome-associated protein MamC. J. Struct. Biol. 2016, 194, 1-9. [CrossRef]

40. Reyes-Ortega, F.; Delgado, Á.; Schneider, E.; Checa Fernández, B.; Iglesias, G. Magnetic Nanoparticles Coated with a Thermosensitive Polymer with Hyperthermia Properties. Polymers 2017, 10, 10. [CrossRef]

41. Mai, B.T.; Balakrishnan, P.B.; Barthel, M.J.; Piccardi, F.; Niculaes, D.; Marinaro, F.; Fernandes, S.; Curcio, A.; Kakwere, H.; Autret, G.; et al. Thermoresponsive Iron Oxide Nanocubes for an Effective Clinical Translation of Magnetic Hyperthermia and Heat-Mediated Chemotherapy. ACS Appl. Mater. Interfaces 2019, 11, 5727-5739. [CrossRef] [PubMed]

42. Sola-Leyva, A.; Jabalera, Y.; Chico-Lozano, M.A.; Carrasco-Jiménez, M.P.; Iglesias, G.R.; Jimenez-Lopez, C. Reactive oxygen species (ROS) production in HepG2 cancer cell line through the application of localized alternating magnetic field. J. Mater. Chem. B 2020. [CrossRef] [PubMed]

43. ISO. Biological Evaluation of Medical Devices_Part 5: Tests for In Vitro Cytotoxicity; International Organization for Standardization: Geneva, Switzerland, 2009.

44. Oltolina, F.; Colangelo, D.; Miletto, I.; Clemente, N.; Miola, M.; Verné, E.; Prat, M.; Follenzi, A. Tumor targeting by monoclonal antibody functionalized magnetic nanoparticles. Nanomaterials 2019, 9, 1575. [CrossRef] [PubMed]

45. Shi, M.; Ho, K.; Keating, A.; Shoichet, M.S. Doxorubicin-conjugated immuno-nanoparticles for intracellular anticancer drug delivery. Adv. Funct. Mater. 2009, 19, 1689-1696. [CrossRef]

(C) 2020 by the authors. Licensee MDPI, Basel, Switzerland. This article is an open access article distributed under the terms and conditions of the Creative Commons Attribution (CC BY) license (http://creativecommons.org/licenses/by/4.0/). 